\title{
Correlation between the overexpression of epidermal growth factor receptor and pathological features of gastric cancer: a meta-analysis
}

\author{
Fan Cui ${ }^{1}$, Xi Zhang ${ }^{2}$ \\ ${ }^{1}$ Department of Clinical Laboratory, The First People's Hospital of Wuhu, Wuhu, China; ${ }^{2}$ Institute of Pathology and Southwest Cancer Center, \\ Southwest Hospital, Third Military Medical University (Army Medical University), Chongqing, China \\ Contributions: (I) Conception and design: X Zhang; (II) Administrative support: F Cui, X Zhang; (III) Provision of study materials or patients: F Cui, \\ X Zhang; (IV) Collection and assembly of data: F Cui, X Zhang; (V) Data analysis and interpretation: F Cui, X Zhang; (VI) Manuscript writing: All \\ authors; (VII) Final approval of manuscript: All authors. \\ Correspondence to: Xi Zhang. Institute of Pathology and Southwest Cancer Center, Southwest Hospital, Third Military Medical University (Army \\ Medical University), No. 30, Gaotanyan Street, Shapingba District, Chongqing 400038, China. Email: cqwzzx628@163.com.
}

\begin{abstract}
Background: To evaluate the overexpression of epidermal growth factor receptor (EGFR) and its correlation with pathological features of gastric cancer, so as to provide a theoretical basis for anti-EGFR targeted therapy.

Methods: PubMed, Embase, Web of Science, CNKI, Wanfang were used to retrieve literature on EGFR expression and gastric cancer tissues between January 2009 and March 2020 and Stata 15.0 software was used to analyze. Age, gender, degree of differentiation, depth of invasion, lymph node metastasis, distant metastasis and TNM staging were analyzed with odds ratio (OR) and $95 \%$ confidence interval (CI).

Results: A total of 17 articles were included, with 4,424 patients with gastric cancer, of which 1,268 patients with EGFR overexpression. EGFR was related to the infiltration depth (OR =3.26, 95\% CI: 1.95-5.44); related to lymph node metastasis (OR =2.10, 95\% CI: 1.45-3.04); related to distant metastasis (OR =1.96, 95\% CI: 1.41-2.72); related to TNM staging (OR =3.98, 95\% CI: 2.09-7.59). However, EGFR overexpression is not concerned with age, gender and differentiation.

Conclusions: EGFR overexpression has the predictive value for depth of invasion, lymph node metastasis, TNM staging and distant metastasis of gastric cancer, and may be a predictor of adverse prognosis of gastric cancer. Targeted therapy for EGFR may be considered as one of the means of comprehensive treatment for gastric cancer.
\end{abstract}

Keywords: Epidermal growth factor receptor (EGFR); gastric cancer; lymph node metastasis; meta-analysis

Submitted May 08, 2020. Accepted for publication Oct 26, 2020.

doi: $10.21037 /$ tcr-20-2035

View this article at: http://dx.doi.org/10.21037/tcr-20-2035

\section{Introduction}

Gastric cancer is one of the most common malignant tumors in the world, with poor prognosis. In recent years, despite its incidence rate has declined, its mortality rate remains high and still poses a serious threat to human health. According to the latest statistics of GLOBOCAN, in 2018, there were about 1.033 million new cases of gastric cancer and 783,000 deaths in the world, ranking fifth in the incidence rate of malignant tumors and third in the mortality rate; the mortality rate was second only to lung cancer and colorectal cancer. Gastric cancer ranks fourth in the incidence rate of male malignant tumors and third in mortality rate while ranks seventh in the incidence rate of female malignant tumors and fifth in the mortality rate (1). According to the latest data from the National Cancer Registry (2), there were 679,000 new cases of 
gastric cancer in China in 2015, including 478,000 males and 201,000 females; about 498,000 cases of gastric cancer died, including 339,000 males and 159,000 females; both the number of cases and deaths ranked second among all malignant tumors. In the United States, there were about 26,000 new cases and 18,800 deaths from gastric cancer in 2018; the number of cases and deaths in the United States were all ranked beyond top 10 in all tumors (3). Epidermal growth factor receptor (EGFR), a member of HER family, participates in regulating cell proliferation, migration, and adhesion, which has become a research hotspot. Many studies have confirmed its positive expression in gastric cancer tissues $(4,5)$. Some studies have also showed EGFR overexpression in gastric cancer patients, which is closely related to pathological staging, lymph node metastasis and prognosis $(6,7)$. However, different studies have different conclusions on the effects of EGFR overexpression on gastric cancer differentiation degree, infiltration depth, TNM staging, lymph node metastasis, and the number of cases in each group is relatively small. Cheng et al. (8) suggested that high expression of EGFR increased lymph node metastasis in gastric cancer patients, while Park et al. (9) asserted that high expression and low expression of EGFR had no effect on lymph node metastasis in gastric cancer patients. Gao et al. (10) believed that high expression of EGFR was not conducive to differentiation of gastric cancer, while Park et al. (9) concluded the opposite. Therefore, this study collected the literature related to EGFR overexpression and clinicopathological characteristics of gastric cancer, and a meta-analysis was performed to further explore their correlation, so as to provide evidence-based medicine basis for the application of anti-EGFR targeted therapy in gastric cancer.

We present the following article in accordance with the PRISMA reporting checklist (available at http://dx.doi. org/10.21037/tcr-20-2035).

\section{Methods}

\section{Sources of literature}

PubMed, Embase, Web of Science, China National Knowledge Infrastructure, Wanfang were searched the relevant literature between January 2009 to March 2020 with "gastric cancer", "erbB1", "Her1", "EGFR", "epidermal growth factor receptor" as keywords. Subsequently, the searched literature was manually screened by reading the abstract and the full text. The language was limited to Chinese and English.

\section{Screening criteria}

\section{Inclusion criteria}

(I) Randomized case-control study published at home and abroad, with original data and using immunohistochemistry (IHC) as detection method. (II) Study on clinicopathological characteristics or prognosis of gastric cancer and EGFR overexpression (note: EGFR positive expression 26-50\% was defined as overexpression, $>50 \%$ was defined as high expression). (III) Study that patients in the study group had clear pathological diagnostic criteria, and all had complete clinicopathological data, and had not received radiotherapy or chemotherapy before surgery; the control group was normal tissues adjacent to cancer or benign diseases. (IV) Study with appropriate statistical method, reliable data, clear results; at least one of the pathological features such as differentiation degree, lymph node metastasis and TNM staging, could calculate the odds ratio (OR) and its $95 \%$ confidence interval (CI). Clinical stage was determined according to the TNM staging criteria formulated by the International Union against Cancer and American Joint Committee on Cancer.

\section{Exclusion criteria}

(I) Other detection methods were applied except IHC, such as qPCR or Western blot. (II) Study subjects were patients with gastric adenoma or carcinoma of esophagogastric junction. (III) Reviews, abstracts, letters, etc. (IV) Repeated reports with the same group of people; studies with poor quality and little information, and the OR and its 95\% CI could not be obtained. (V) Newcastle-Ottawa Scale (NOS) score $<6$.

\section{Literature quality evaluation}

The full text of literature was read carefully, and the quality of the literature was evaluated according to the NOS (11). The literature below 6 stars was of low quality and above 6 stars was of high quality. Only the literature above 6 stars were included in this study. Two evaluators independently evaluated in accordance with the unified quality standard to extract literature and then cross-check. The disagreement between the two evaluators was resolved by discussion or with the assistance of a third researcher. 


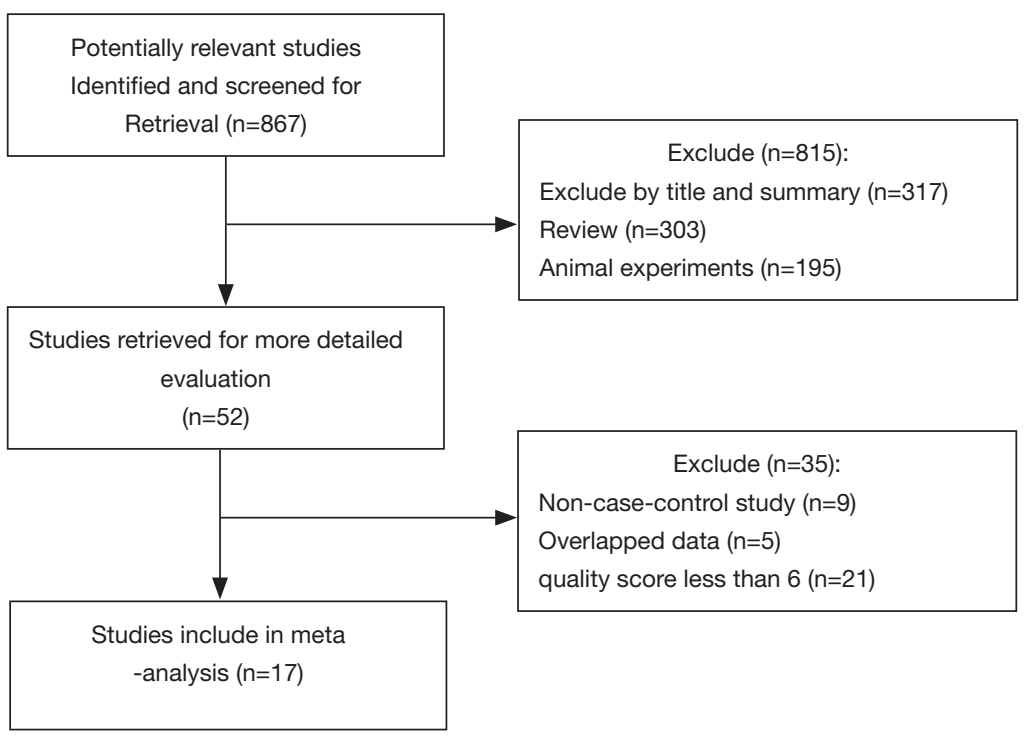

Figure 1 A flow diagram of the literature screening process.

\section{Data extraction}

Relevant information extracted using a unified data extraction table includes: (I) general information: title, first author, year of publication; (II) study characteristics: gender, age, expression of EGFR, differentiation degree, depth of invasion, lymph node metastasis, distant metastasis and TNM staging; (III) methodological information: detection method of EGFR in tissues.

\section{Statistical analysis}

Meta-analysis was carried out using Stata 15.0 software. The OR and $95 \%$ CI were calculated as effect sizes to represent the results. Q test was applied to examine the heterogeneity of each research result. $\mathrm{I}^{2} \geq 50 \%$, or $\mathrm{P} \leq 0.05$ indicated heterogeneity, so the random effect model (REM) was adopted; otherwise, fixed effect model (FEM) was used. $Z$ test was used for the significance test of the pooled OR. In this meta-analysis, funnel plot was used to assess the publication bias of included literature. The funnel plot uses the standard error of each research $\log (\mathrm{OR})$ to make a graph of its OR. If the funnel plot was asymmetric, there may be publication bias, and then Egger's test was applied to examine publication bias. Eventually, sensitivity analysis was conducted to assess the robustness of the results.

\section{Results}

\section{Literature retrieval results}

The databases were searched comprehensively, and the results were cross-checked. After reading, the searched studies were screened strictly in line with the inclusion and exclusion criteria and quality requirements. Ultimately, 17 studies $(8-10,12-25)$ were included in this meta-analysis. The specific screening process was shown in Figure 1. The basic characteristics of the included literature were shown in Table 1. A total of 4,424 gastric cancer patients were included, including 1,268 positive cases (28.66\%).

\section{Relationship between EGFR overexpression and clinicopatbological characteristics of gastric cancer}

\section{Relationship between EGFR overexpression and the depth of invasion}

A total of 17 literature on EGFR overexpression and depth of invasion was included, including 1,975 cases with extraserosal invasion and 1,271 cases with subserosal invasion. The heterogeneity among the studies was significant $\left(\mathrm{I}^{2}=73.3 \%\right)$, so REM was adopted (Table 2 ). The difference between the two groups was statistically significant, with subserosal invasion cases as the control group $(\mathrm{OR}=3.26,95 \% \mathrm{CI}$ : $1.95-5.44, \mathrm{P}<0.001)$ (Figure $2 A)$. 
Table 1 Basic characteristics of the included literature on the relationship between EGFR and gastric cancer

\begin{tabular}{|c|c|c|c|c|c|}
\hline First author & Year & $\begin{array}{l}\text { EGFR positive } \\
\text { expression, } \mathrm{n}(\%)\end{array}$ & $\begin{array}{l}\text { EGFR testing } \\
\text { method }\end{array}$ & Clinicopathological features & NOS score \\
\hline Czyzewska & 2009 & $30(54.55)$ & IHC & $\begin{array}{l}\text { Gender, age, degree of differentiation, depth of invasion, } \\
\text { lymph node metastasis }\end{array}$ & 8 \\
\hline Inokuchi & 2009 & $37(29.37)$ & $\mathrm{IHC}$ & Gender, lymph node metastasis, distant metastasis & 8 \\
\hline Chen & 2012 & $53(84.13)$ & IHC & $\begin{array}{l}\text { Gender, degree of differentiation, depth of invasion, lymph } \\
\text { node metastasis, TNM stage }\end{array}$ & 7 \\
\hline Al-Moundhri & 2012 & $16(13.91)$ & $\mathrm{IHC}$ & $\begin{array}{l}\text { Gender, age, degree of differentiation, depth of invasion, } \\
\text { lymph node metastasis, TNM stage }\end{array}$ & 8 \\
\hline Zhang & 2011 & $47(55.95)$ & $\mathrm{IHC}$ & $\begin{array}{l}\text { Gender, age, degree of differentiation, depth of invasion, } \\
\text { lymph node metastasis, distant metastasis, TNM stage }\end{array}$ & 7 \\
\hline Atmaca & 2012 & $152(42.58)$ & IHC & Gender, lymph node metastasis & 8 \\
\hline $\mathrm{Ma}$ & 2014 & $38(57.58)$ & $\mathrm{IHC}$ & $\begin{array}{l}\text { Gender, age, depth of invasion, lymph node metastasis, } \\
\text { TNM stage, distant metastasis }\end{array}$ & 8 \\
\hline Kurokawa & 2014 & $22(14.38)$ & $\mathrm{IHC}$ & $\begin{array}{l}\text { Gender, degree of differentiation, depth of invasion, lymph } \\
\text { node metastasis }\end{array}$ & 8 \\
\hline Nagatsuma & 2015 & $223(23.47)$ & $\mathrm{IHC}$ & $\begin{array}{l}\text { Gender, depth of invasion, lymph node metastasis, TNM } \\
\text { stage }\end{array}$ & 8 \\
\hline Tang & 2014 & $30(27.03)$ & IHC & Gender, depth of invasion, lymph node metastasis & 8 \\
\hline Yang & 2016 & $59(48.76)$ & $\mathrm{IHC}$ & $\begin{array}{l}\text { Gender, age, degree of differentiation, depth of invasion, } \\
\text { lymph node metastasis }\end{array}$ & 7 \\
\hline Oono & 2019 & $32(8.53)$ & $\mathrm{IHC}$ & Gender, degree of differentiation, depth of infiltration & 8 \\
\hline Moghbeli & 2019 & $23(46.00)$ & $\mathrm{IHC}$ & $\begin{array}{l}\text { Gender, degree of differentiation, depth of invasion, lymph } \\
\text { node metastasis, TNM stage }\end{array}$ & 8 \\
\hline
\end{tabular}

EGFR, epidermal growth factor receptor; IHC, immunohistochemistry; NOS, Newcastle-Ottawa Scale.

The result indicated that with the enhancement of EGFR expression, the deeper the depth of invasion of gastric cancer.

\section{Relationship between EGFR overexpression and lymph node metastasis}

A total of 16 literature on EGFR overexpression and lymph node metastasis was included, including 2,615 cases with lymph node metastasis and 1,396 cases without lymph node metastasis. The heterogeneity among the studies was significant $\left(\mathrm{I}^{2}=69.9 \%\right)$, so REM was adopted (Table 2 ). The difference between the two groups was statistically significant, taking the cases without lymph node metastasis as the control group ( $\mathrm{OR}=2.10,95 \% \mathrm{CI}: 1.45-3.04$, $\mathrm{P}<0.001$ ) (Figure $2 B$ ). This result indicated that with the enhancement of EGFR expression, the higher the risk of 
Table 2 Meta-analysis of EGFR overexpression and pathological characteristics of gastric cancer

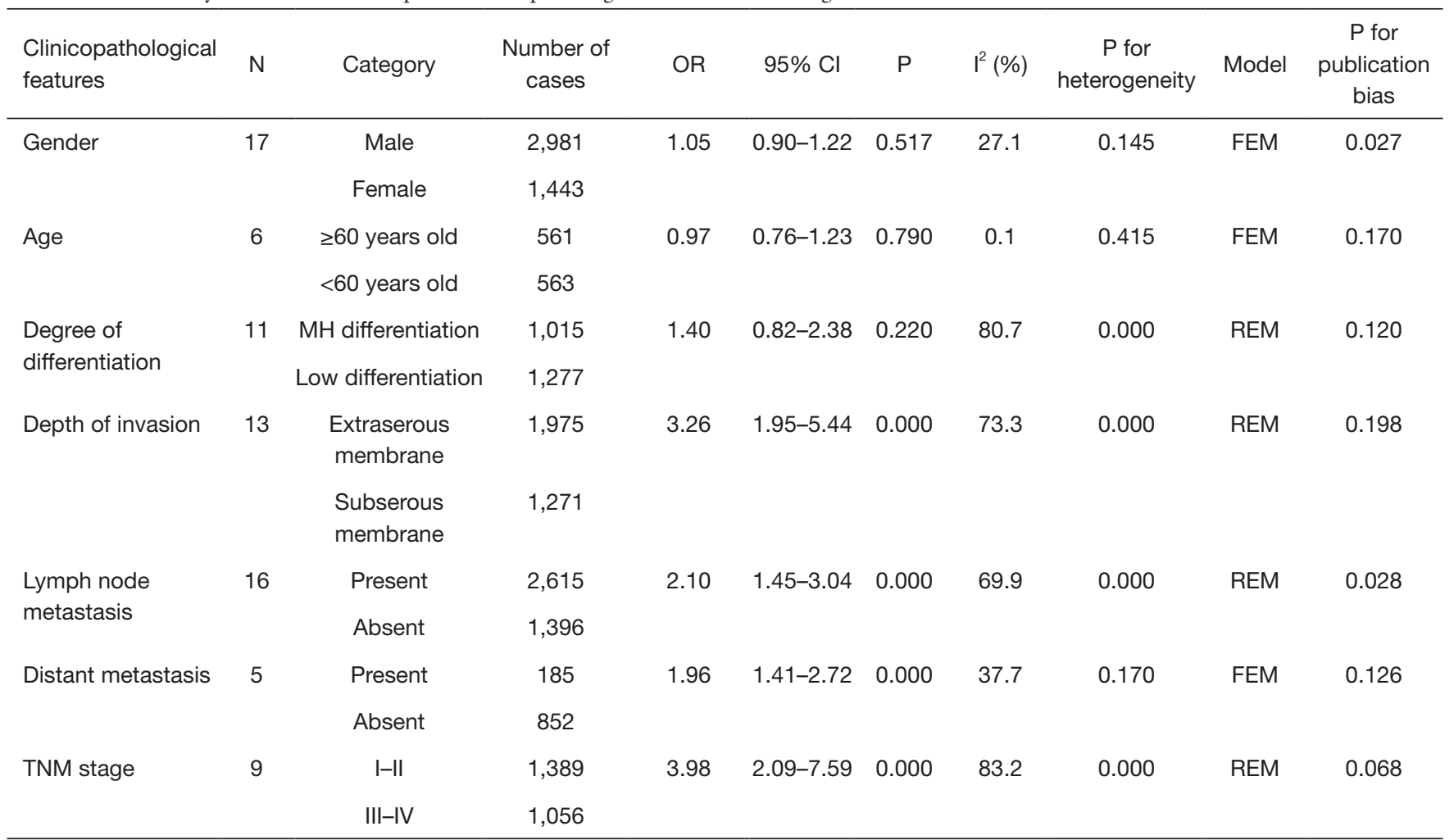

EGFR, epidermal growth factor receptor; OR, odds ratio; Cl, confidence interval; FEM, fixed effect model; REM, random effect model; $\mathrm{MH}$, middle and high.

lymph node metastasis of gastric cancer.

\section{Relationship between EGFR overexpression and distant metastasis}

A total of five literature on EGFR overexpression and distant metastasis was included, including 185 cases with distant metastasis and 852 cases without distant metastasis. There was no statistical heterogeneity between the two groups $\left(I^{2}=37.7 \%\right)$, so FEM was adopted (Table 2). The difference between the two groups was statistically significant, taking the cases without distant metastasis as the control group (OR $=1.96,95 \%$ CI: 1.41-2.72, $\mathrm{P}<0.001$ ) (Figure 2C). This result indicated that with the enhancement of EGFR expression, the higher the risk of distant metastasis of gastric cancer.

\section{Relationship between EGFR overexpression and TNM staging}

A total of nine literature on EGFR overexpression and TNM staging was included, including 1,389 patients in stage I + II and 1,056 patients in stage III + IV. The heterogeneity among the studies was significant $\left(I^{2}=83.2 \%\right)$, so REM was adopted (Table 2). The difference between the two groups was statistically significant, with the patients in stage I + II as the control group (OR $=3.98,95 \%$ CI: 2.09-7.59, $\mathrm{P}<0.001$ ) (Figure 2D). This result indicated that with the enhancement of EGFR expression, the deeper the depth of invasion of gastric cancer.

\section{Relationship between EGFR overexpression and gender, age and degree of differentiation}

The corresponding statistical model was selected according to the presence or absence of heterogeneity. The heterogeneity test of differentiation degree showed that $\mathrm{P}<0.05$, so REM was adopted (Table 2). As shown in Table 2, there was no correlation between EGFR overexpression and gender, age and differentiation degree $(\mathrm{P}>0.05)$.

\section{Publication bias analysis}

Funnel plot analysis was carried out on the included literature, and the symmetry of funnel plot was analyzed by Egger's test (Table 2, Figure 3). The results showed that 
A

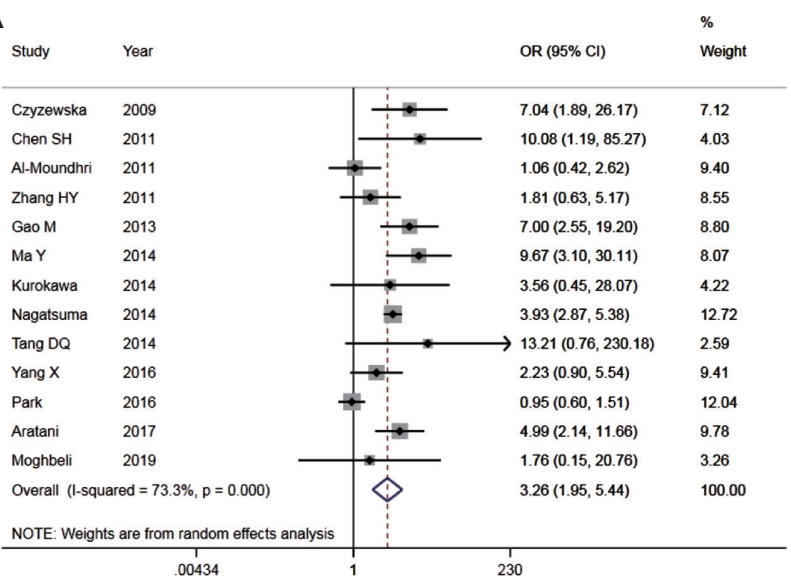

C

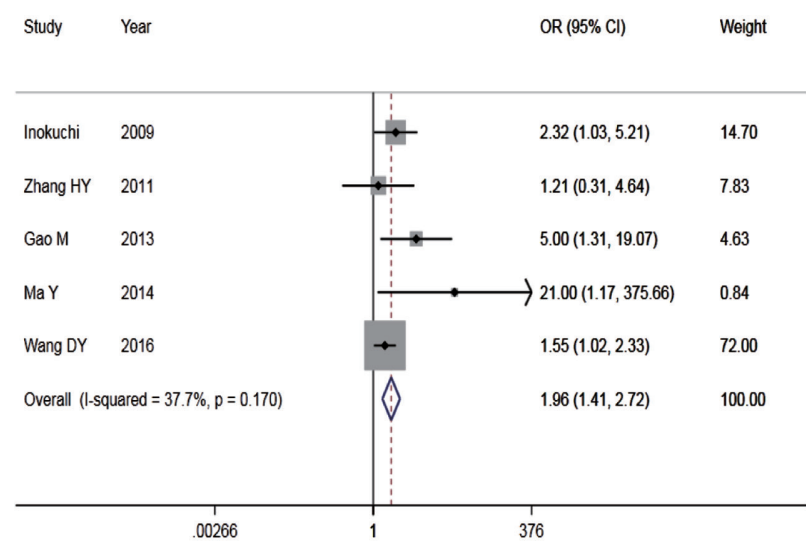

B

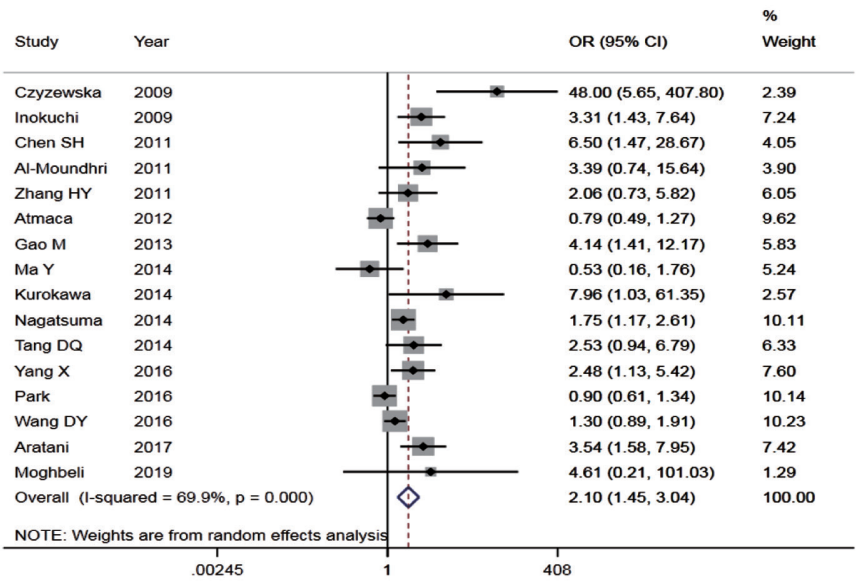

D

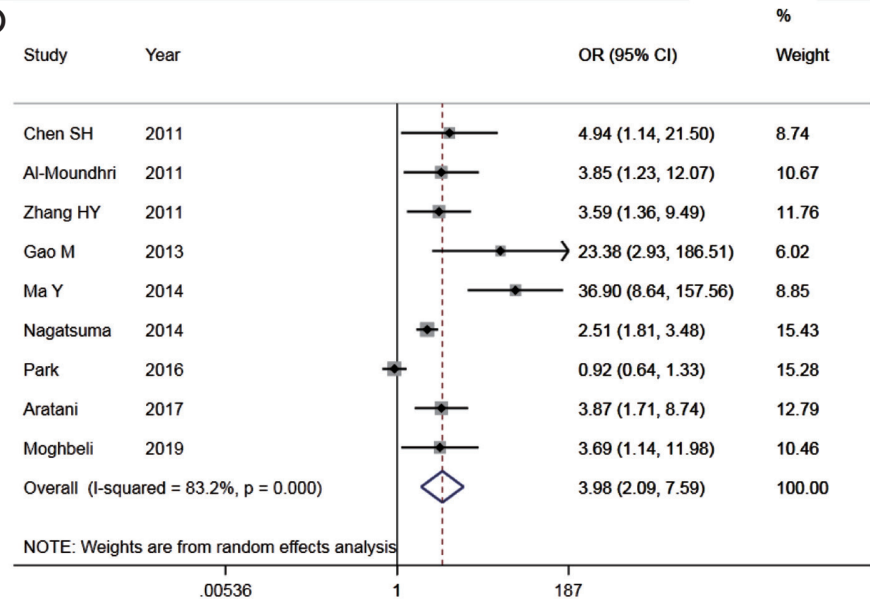

Figure 2 Forest plots of meta-analysis of the relationship between EGFR overexpression and gastric cancer. (A) EGFR and depth of invasion; (B) EGFR and lymph node metastasis; (C) EGFR and distant metastasis; (D) EGFR and TNM staging. EGFR, epidermal growth factor receptor; OR, odds ratio; CI, confidence interval.

there was no publication bias in age, distant metastasis, TNM staging and differentiation degree, while there was partial publication bias in gender and lymph node metastasis.

\section{Sensitivity analysis}

As shown in Figure 4, after removing a single study in turn, there was no statistically significant change in the meta-analysis outcome of the research indicators such as differentiation degree, depth of invasion, lymph node metastasis, distant metastasis and TNM staging. This showed that the results of this study were robust.

\section{Discussion}

At present, surgery, radiotherapy and chemotherapy are the main treatment methods for gastric cancer. Although great progress has been made in the diagnosis and treatment of gastric cancer, its morbidity and mortality are still relatively high. EGFR belongs to tyrosine kinase type I receptor family. Members of this family not only act as receptors, but also can convert extracellular signals into intracellular effects (26), which play an important role in tumor progression. EGFR regulates cell proliferation, induces and promotes tumor growth by activating MAPK/ ERK, EGFR-STAT3, PI3K-Akt and other pathways, which is closely related to the occurrence of more than $33 \%$ 

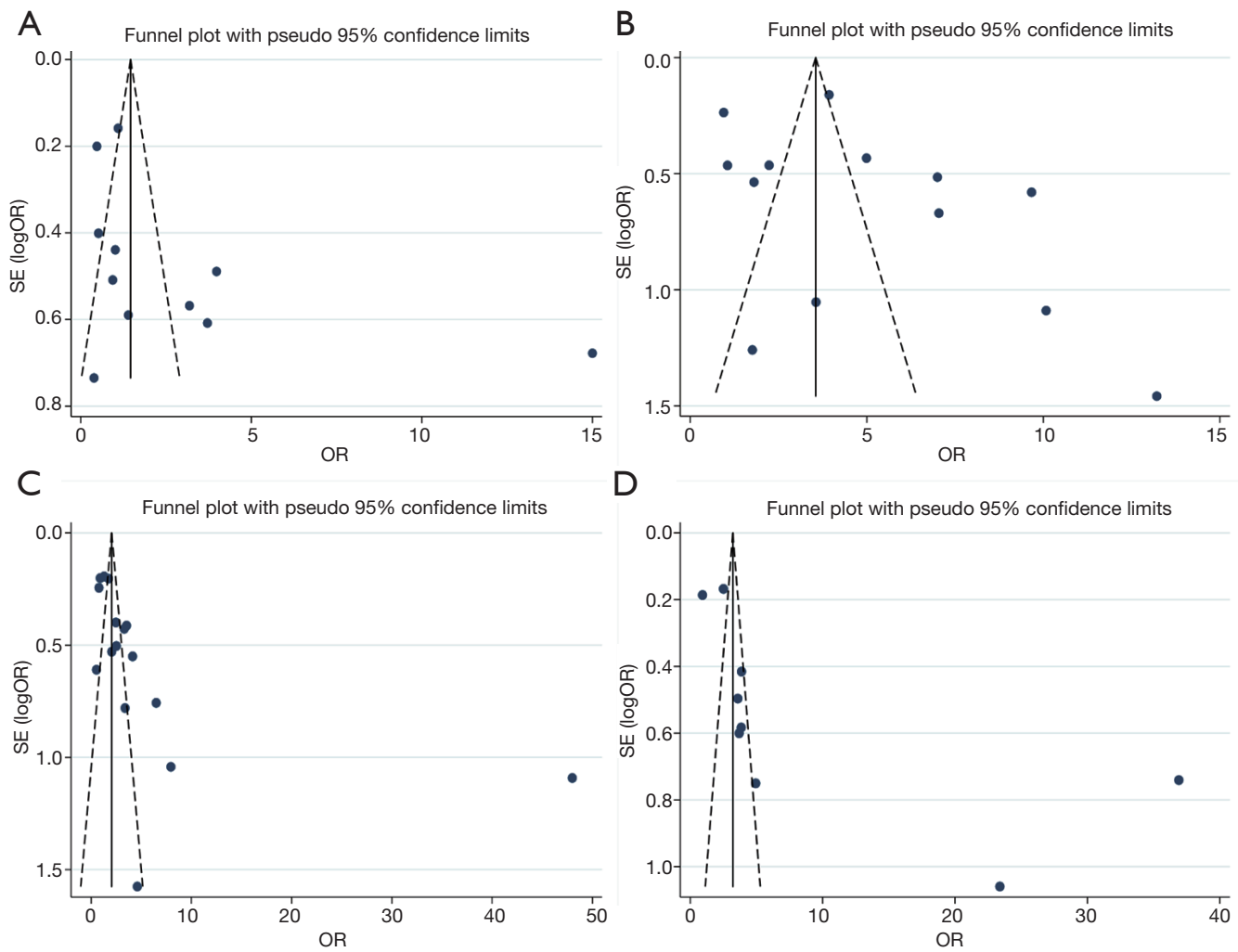

Figure 3 Funnel plots of meta-analysis of the relationship between EGFR overexpression and gastric cancer. (A) Degree of differentiation; (B) EGFR and depth of invasion; (C) EGFR and lymph node metastasis; (D) EGFR and TNM stage. EGFR, epidermal growth factor receptor; OR, odds ratio; SE, standard error.

epidermal tumors (27). In the 21 st century, the research on clinical transformation of targeted drugs is developing rapidly and targeted therapy is critical in the comprehensive treatment of multiple advanced solid tumors. EGFR is also the most important target molecule discovered so far $(28,29)$. A large number of studies have confirmed that EGFR is overexpressed in head and neck tumors, breast cancer, nonsmall cell lung cancer, colorectal cancer, ovarian cancer and other tumors, which are closely related to tumor cell proliferation, invasion, metastasis, vascular growth and apoptosis (30-34). Therefore, EGFR has gradually become one of the main targets for tumor therapy today. However, through searching the relevant domestic and foreign literature in the past 10 years, the studies on the EGFR expression and the clinical characteristics are still lack of large samples of clinical and pathological data, and the conclusions are inconsistent. According to the inclusion and exclusion criteria, 17 high-quality literature (NOS score $\geq 6$ ) is included in this meta-analysis. It provided more comprehensive data to explore the relationship between EGFR overexpression and clinicopathological characteristics of gastric cancer.

Previous studies have found that EGFR gene expression rate is closely related to the depth of invasion, cell differentiation, lymph node metastasis, TNM staging of gastric cancer, but not to the adjacent tissues (35). Kopp et al. showed that compared with adjacent normal gastric mucosa, EGFR level was increased in gastric cancer tissues, especially in T4 stage cancers, tumors with positive lymph node metastasis, advanced cancers and undifferentiated cancers (36). Invasion depth, lymph node metastasis, tissue differentiation and clinical stage are the factors of invasion and metastasis of gastric cancer, reflecting the progress of gastric cancer and survival and prognosis of patients. Previous studies have shown that overexpression of EGFR is associated with poor prognosis of gastric cancer, and EGFR has the effects on the progression of tumor and ultimately affects the prognosis of patients $(4,10)$.

A total of 17 articles were included in this meta-analysis, including 4,424 gastric cancer patients, and the overall 
A

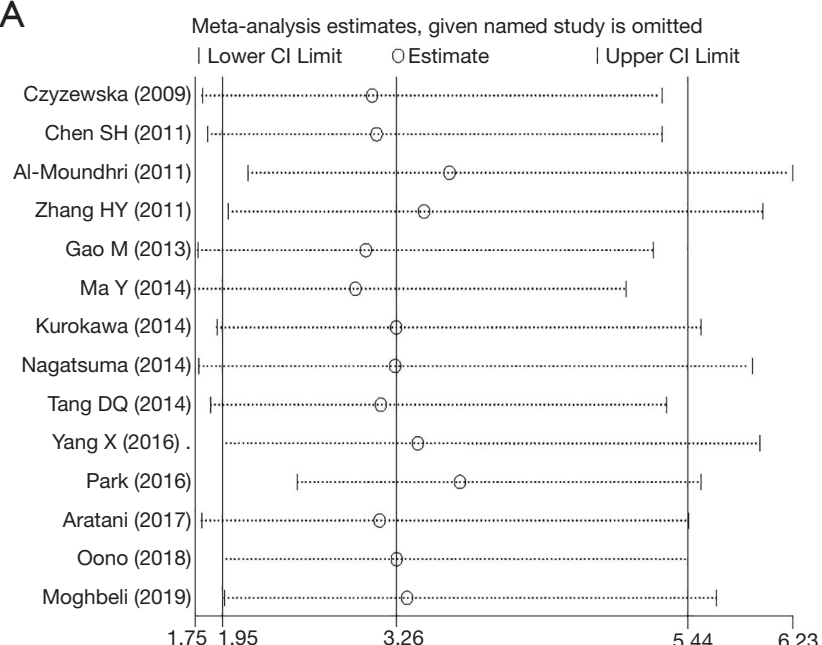

C

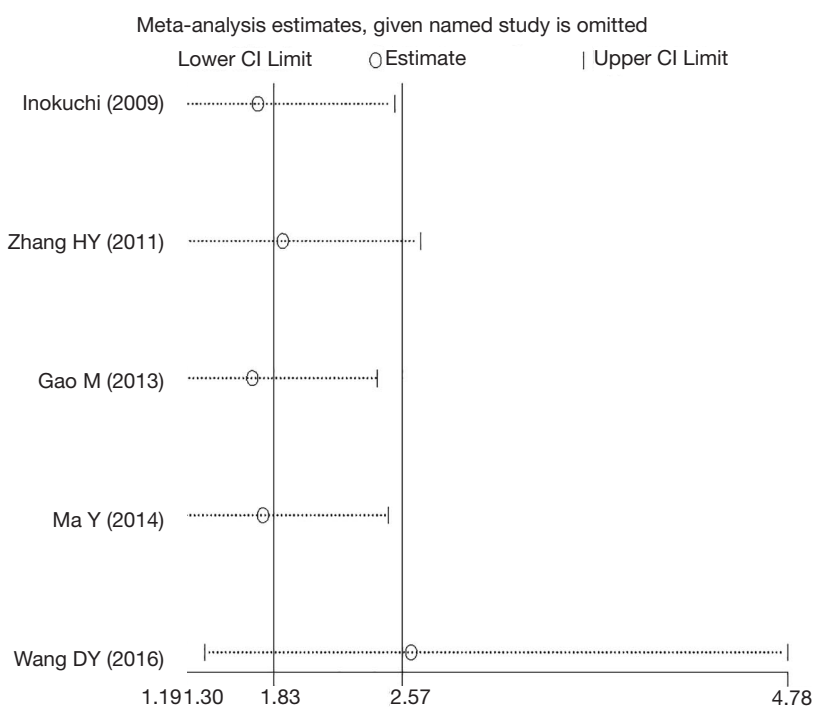

B
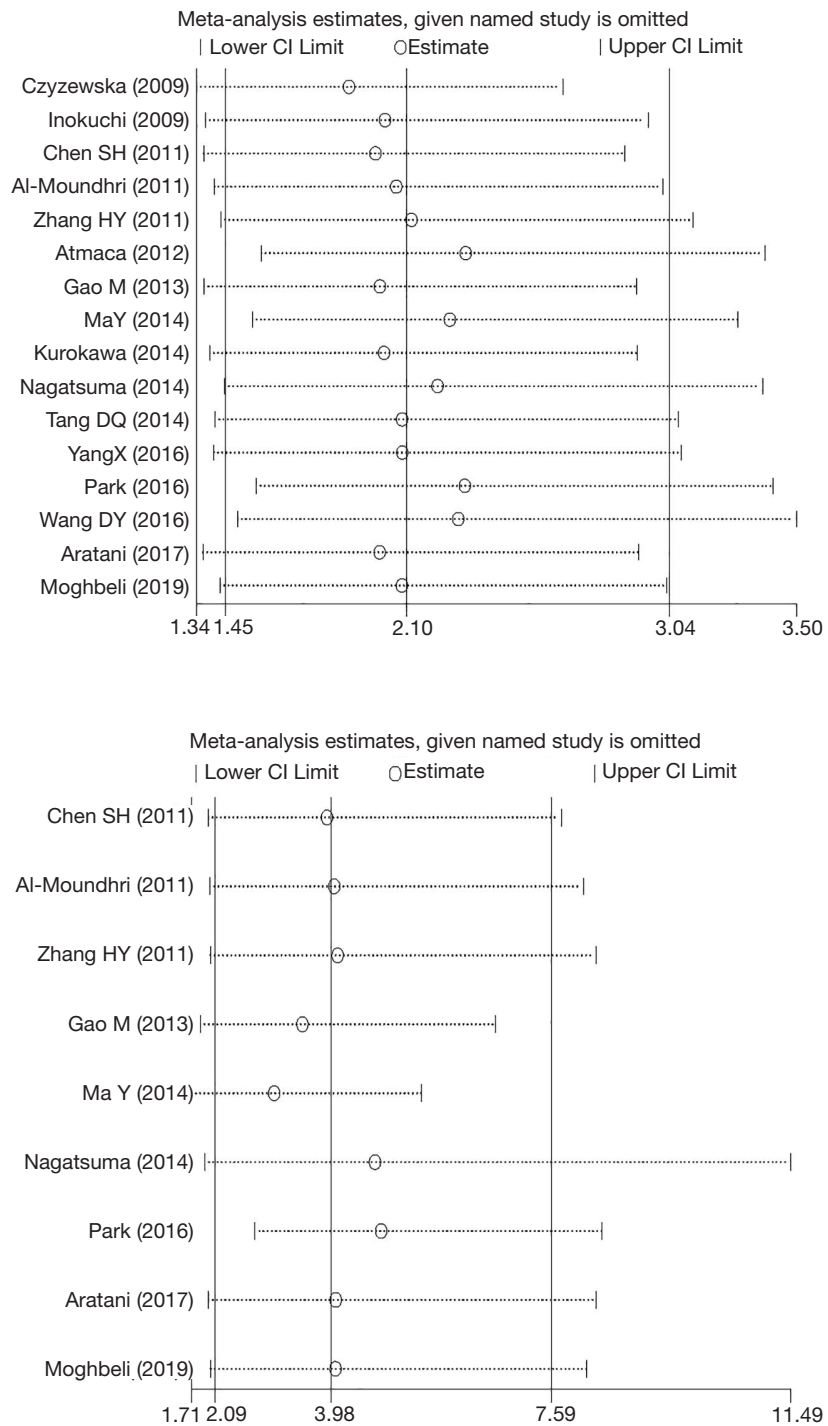

Figure 4 Sensitivity analysis. (A) EGFR and depth of invasion; (B) EGFR and lymph node metastasis; (C) EGFR and distant metastasis; (D) EGFR and TNM staging. EGFR, epidermal growth factor receptor; CI, confidence interval.

positive rate of EGFR was $28.66 \%$. The results showed that EGFR overexpression was correlated with depth of invasion, lymph node metastasis, distant metastasis and TNM staging of gastric cancer, that is, it had predictive value for the above indicators, while EGFR overexpression had no relation with differentiation degree, age and gender. In term of heterogeneity, there is no significant heterogeneity in age, gender and distant metastasis, while there is some heterogeneity in differentiation degree, infiltration depth, lymph node metastasis and TNM staging. In term of publication bias, gender and lymph node metastasis have certain publication bias, and other indicators have no obvious publication bias. Sensitivity analysis results showed that after removing a single study in turn, there was no statistically significant change in the results of metaanalysis on the research indicators such as infiltration depth, lymph node metastasis, distant metastasis and TNM staging of gastric cancer, which indicated that the results were stable. This indicated that the conclusions of this metaanalysis were relatively reliable. Meta-analysis by Zhang et al. (37) showed that EGFR overexpression was correlated with differentiation degree, but not with depth of invasion. The result of Zhang was not very consistent with our conclusions. In this meta-analysis, EGFR overexpression 
was not related to the degree of differentiation, but to depth of invasion, which was also confirmed by sensitivity analysis. This result may be related to the inclusion of more high-quality literature in our study. In addition, EGFR overexpression was also confirmed to be associated with distant metastasis.

This study also has some limitations. (I) The scoring criteria of IHC for EGFR expression detection are different among the studies; and there are certain subjectivity and inconsistency in judging the positive expression among different researchers. The above factors may lead to potential bias and thus affect the accuracy of the results. (II) There is a certain publication bias in gender and lymph node metastasis. (III) The degree of differentiation, infiltration depth, lymph node metastasis and TNM staging have certain heterogeneity, which may be related to race or gastric cancer staging. (IV) Although IHC is applied to detect the EGFR expression in all included studies, the antibody manufacturers, dilution concentrations and judgement criteria are not completely consistent, thus affecting the results of meta-analysis. (V) The number of included studies is limited and may not cover all relevant studies comprehensively.

In conclusion, the results of this study reveal that the high expression of EGFR in gastric cancer tissues is correlated with the depth of invasion, lymph node metastasis, distant metastasis and TNM staging of gastric cancer. Therefore, we hypothesize that anti-EGFR targeted therapy combined with radiotherapy and chemotherapy is likely to achieve certain results in the comprehensive treatment of gastric cancer. Of course, because this study still has certain limitations and is not consistent with metaanalysis published in the past, more clinical researches are required and the prognosis should be observed, so as to make a more in-depth and comprehensive study on the effect of EGFR overexpression on gastric cancer and to provide more sufficient theoretical basis for the application of anti-EGFR targeted therapy in gastric cancer.

\section{Acknowledgments}

Funding: Study on the molecular mechanism of the relationship between insulin and insulin-like growth factor in diabetic patients (201907d07050010).

\section{Footnote}

Reporting Checklist: The authors have completed the
PRISMA reporting checklist. Available at http://dx.doi. org/10.21037/tcr-20-2035

Conflicts of Interests: Both authors have completed the ICMJE uniform disclosure form (available at http://dx.doi. org/10.21037/tcr-20-2035). The authors have no conflicts of interest to declare.

Ethical Statement: The authors are accountable for all aspects of the work in ensuring that questions related to the accuracy or integrity of any part of the work are appropriately investigated and resolved.

Open Access Statement: This is an Open Access article distributed in accordance with the Creative Commons Attribution-NonCommercial-NoDerivs 4.0 International License (CC BY-NC-ND 4.0), which permits the noncommercial replication and distribution of the article with the strict proviso that no changes or edits are made and the original work is properly cited (including links to both the formal publication through the relevant DOI and the license). See: https://creativecommons.org/licenses/by-nc-nd/4.0/.

\section{References}

1. Bray F, Ferlay J, Soerjomataram I, et al. Global cancer statistics 2018: GLOBOCAN estimates of incidence and mortality worldwide for 36 cancers in 185 countries. CA Cancer J Clin 2018;68:394-424.

2. Chen W, Zheng R, Baade PD, et al. Cancer statistics in China, 2015. CA Cancer J Clin 2016;66:115-32.

3. Siegel RL, Miller KD, Jemal A. Cancer statistics, 2018. CA Cancer J Clin 2018;68:7-30.

4. Terashima M, Kitada K, Ochiai A, et al. Impact of expression of human epidermal growth factor receptors EGFR and ERBB2 on survival in stage II/III gastric cancer. Clin. Cancer Res. 2012;18:5992-6000.

5. He C, Bian XY, Ni XZ, et al. Correlation of human epidermal growth factor receptor 2 expression with clinicopathological characteristics and prognosis in gastric cancer. World J Gastroenterol 2013;19:2171-8.

6. Kim MA, Lee HS, Lee HE, et al. EGFR in gastric carcinomas: prognostic significance of protein overexpression and high gene copy number. Histopathology 2008;52:738-46.

7. Ema A, Waraya M, Yamashita K, et al. Identification of EGFR expression status association with metastatic lymph node density (ND) by expression microarray analysis of 
advanced gastric cancer. Cancer Med 2015;4:90-100.

8. Cheng SH, Bai YX, Tao L. Expression of Maspin and EGFR in gastric cancer and its clinical significance. China Cancer 2012;21:71-4.

9. Park JS, Kim HS, Bae YS, et al. Prognostic significance and frequency of EGFR expression and amplification in surgically resected advanced gastric cancer. Jpn J Clin Oncol 2016;46:507-16.

10. Gao M, Liang XJ, Zhang ZS, et al. Relationship between expression of EGFR in gastric cancer tissue and clinicopathological features. Asian Pac J Trop Med 2013;6:260-4.

11. Stang A. Critical evaluation of the Newcastle-Ottawa scale for the assessment of the quality of nonrandomized studies in meta-analyses. Eur J Epidemiol 2010;25:603-5.

12. Czyzewska J, Guzinska-Ustymowicz K, Kemona A. Correlation of c-erbB-2, EGF and EGFR expression with postoperative survival of patients with advanced carcinoma of the stomach. Folia Histochem Cytobiol 2009;47:653-61.

13. Inokuchi M, Murayama T, Hayashi M, et al. Prognostic value of co-expression of STAT3, mTOR and EGFR in gastric cancer. Exp Ther Med 2011;2:251-6.

14. Zhang HY, Tao HM, Chen HT. Expression and clinical significance of epidermal growth factor receptor and protein kinase B in gastric carcinoma. Zhonghua Wei Chang Wai Ke Za Zhi 2011;14:140-2.

15. Al-Moundhri MS, Al-Hadabi I, Al-Mawaly K, et al. Prognostic significance of cyclooxygenase-2, epidermal growth factor receptor 1 , and microvascular density in gastric cancer. Med Oncol 2012;29:1739-47.

16. Atmaca A, Werner D, Pauligk C, et al. The prognostic impact of epidermal growth factor receptor in patients with metastatic gastric cancer. BMC Cancer 2012;12:524.

17. Tang D, Liu CY, Shen D, et al. Assessment and prognostic analysis of EGFR, HER2, and HER3 protein expression in surgically resected gastric adenocarcinomas. Onco Targets Ther 2014;8:7-14.

18. Kurokawa Y, Matsuura N, Kawabata R, et al. Prognostic impact of major receptor tyrosine kinase expression in gastric cancer. Ann Surg Oncol 2014;21 Suppl 4:S584-90.

19. Ma Y, Song YL, Bao Y. Expression of EGFR, Her-2, VEGF and IGF-1R in gastric cancer and their correlation with clinicopathogical parameters. Journal of Harbin Medical University 2014;48:191-4.

20. Nagatsuma AK, Aizawa M, Kuwata T, et al. Expression profiles of HER2, EGFR, MET and FGFR2 in a large cohort of patients with gastric adenocarcinoma. Gastric
Cancer 2015;18:227-38.

21. Yang X, He T, He SL, et al. Expression and clinical significance of CXCL14 and EGFR in human gastric cancer. Chin J Clin Oncol 2016;43:860-4.

22. Wang D, Wang B, Wang R, et al. High expression of EGFR predicts poor survival in patients with resected $\mathrm{T} 3$ stage gastric adenocarcinoma and promotes cancer cell survival. Oncol Lett 2017;13:3003-13.

23. Aratani K, Komatsu S, Ichikawa D, et al. Overexpression of EGFR as an independent prognostic factor in adenocarcinoma of the esophagogastric junction. Anticancer Res 2017;37:3129-35.

24. Oono Y, Kuwata T, Takashima K, et al. Human epidermal growth factor receptor 2-, epidermal growth factor receptor-, and mesenchymal epithelial transition factorpositive sites of gastric cancer using surgical samples. Gastric Cancer 2019;22:335-43.

25. Moghbeli M, Makhdoumi Y, Soltani Delgosha M, et al. ErbB1 and ErbB3 co-over expression as a prognostic factor in gastric cancer. Biol Res 2019;52:2.

26. Zwick E, Bange J, Ullrich A. Receptor tyrosine kinase signalling as a target for cancer intervention strategies. Endocr Relat Cancer 2001;8:161-73.

27. Mendelsohn J, Baselga J. Status of epidermal growth factor receptor antagonists in the biology and treatment of cancer. J Clin Oncol 2003;21:2787-99.

28. Hong L, Han Y, Brain L. The role of epidermal growth factor receptor in prognosis and treatment of gastric cancer. Expert Rev Gastroenterol Hepatol 2014;8:111-7.

29. Szokol B, Gyulavari P, Baska F, et al. Development and biochemical characterization of EGFR/c-Met dual inhibitors. Acta Pharm Hung 2013;83:121-33.

30. Alterio D, Marvaso G, Maffini F, et al. Role of EGFR as prognostic factor in head and neck cancer patients treated with surgery and postoperative radiotherapy: proposal of a new approach behind the EGFR overexpression. Med Oncol 2017;34:107.

31. Lee HJ, Seo AN, Kim EJ, et al. Prognostic and predictive values of EGFR overexpression and EGFR copy number alteration in HER2-positive breast cancer. Br J Cancer 2015;112:103-11.

32. Xu N, Fang W, Mu L, et al. Overexpression of wildtype EGFR is tumorigenic and denotes a therapeutic target in non-small cell lung cancer. Oncotarget 2016;7:3884-96.

33. Yun S, Kwak Y, Nam SK, et al. Ligand-independent epidermal growth factor receptor overexpression correlates with poor prognosis in colorectal cancer. Cancer Res Treat 2018;50:1351-61. 
34. Zhang M, Cong Q, Zhang XY, et al. Pyruvate dehydrogenase kinase 1 contributes to cisplatin resistance of ovarian cancer through EGFR activation. J Cell Physiol 2019;234:6361-70.

35. Baoxiang B, Yitong Z, Miao Y, et al. Expression and clinical value of HER2 and EGFR in gastric cancer. Journal of Bethune Military Medical College 2011;9:249-51.

Cite this article as: Cui F, Zhang $\mathrm{X}$. Correlation between the overexpression of epidermal growth factor receptor and pathological features of gastric cancer: a meta-analysis. Transl Cancer Res 2021;10(1):406-416. doi: 10.21037/tcr-20-2035
36. Kopp R, Ruge M, Rothbauer E, et al. Impact of epidermal growth factor (EGF) radioreceptor analysis on longterm survival of gastric cancer patients. Anticancer Res 2002;22:1161-7.

37. Zhang Z, Tang H, Lin J, et al. Clinicopathologic and prognostic significance of human epidermal growth factor receptor in patients with gastric cancer: an updated metaanalysis. Oncotarget 2017;8:17202-15. 